\title{
Recent finds of Entorrhiza root smuts
}

Arthur Chater, Windover, Penyrangor, Aberystwyth, SY23 1BJ.

aochater4@gmail.com

Paul A. Smith, S3RI, University of Southampton, Highfield, Southampton, SO17 1BJ.

p.a.smith@soton.ac.uk

Entorrhiza is an obscure genus of fungi with about 14 species worldwide, obscure because their only visible manifestation is the production of sori as galls on the roots of the host plants, because their systematic position is uncertain, and because they are understandably rarely collected and five of the species are known only from the type collection (Fineran 1978, Vanky 2012). Traditionally considered to be smuts, the genus has recently (Bauer et al. 2015) been assigned to a new fungal phylum, the Entorrhyzomycota, on the basis of multiple gene sequencing. The hosts are members of the Cyperaceae and Juncaceae, and five species are now known from Britain. The galls, one to several per plant, are usually up to about $8 \mathrm{~mm}$ long, occasionally up to $14 \mathrm{~mm}$, attached to the tips of slender root branches and initially conspicuously white though becoming progressively dark brown with age from the attachment end as the spores ripen.

E. aschersoniana occurs on Juncus bufonius, the galls being oblong to globose (Fig. 1). The spores are very variable, though mostly subglobose or ovoid, most being very conspicuously and coarsely warted while others are more or less smooth (Fig. 3). Recorded until recently only from Aberdeen in the $19^{\text {th }}$ century and from Mull in 1968 (FRDBI www.fieldmycology.net/frdbi/frdbi.asp, accessed 3 Sep 2017), it was found in the Outer Hebrides (vc110) on a plant on a roadside verge at Arnol, Lewis by PAS on 28 July 2016, and in 2017 in a gateway at Cairinis, North Uist. In August 2017 it was found by $A O C$ to be frequent throughout much of Cardiganshire (vc46) and into adjacent Carmarthenshire (vc44), Montgomeryshire (vc47), Merioneth (vc48) and at the margin of Rushmere pond on Wimbledon Common, Surrey (vc17); Ray Woods and Andy Shaw have found it in Breconshire (vc42). It is recorded altogether from 37 tetrads in mid-Wales. In Wales it occurs chiefly where the host grows in gravelly or peaty soil at the edges of roads or tracks where the ground is sloping and there is some movement of water (Fig. 2), presumably facilitating the distribution of the spores (Zwetko \& Blanz 2004, Bauer et al. 2015), but it has also been found in a vegetable plot where the host may have come in as seed in horse droppings collected for manure. It has not yet been found in any entirely natural habitat here, unlike in Surrey, nor has it been found on its other known hosts Juncus ranarius and $J$. minutulus.

E. casparyana var. casparyana primarily infects Juncus articulatus, and there are some early reports from near Glasgow (Trail 1884) and from Kent (Schwartz 1910) which are likely to have been this species but whose exact identity is in doubt. There are two records on FRDBI, both made by RWG Dennis in NW Scotland. PAS searched for infected J. articulatus in vc110 in 2017, and found it in two locations near to each other, but in separate tetrads in North Harris. Both were in peaty flushes over a gravelly substrate (Fig. 5). Searches by AOC in mid Wales in autumn 2017 have so far resulted in finds in 30 tetrads on both J. articulatus var. articulatus and var. nigritellus, in similar sites to $E$. aschersoniana (Fig. 2) and in all the same vice-counties as well as in Radnorshire (vc43). The galls are often larger and more lobed than in the other British species (Fig. 6). The spores (Fig. 4) are mostly strongly warted like those of $E$. aschersoniana, though rather more are smooth than in that species, all are strictly globose, and a few of the largest are very thick-walled.

E. caricicola is known in Europe from Denmark and Sweden on Carex limosa and Juncus filiformis, and on other species in New Zealand. It was found in August 2017 by AOC on Carex limosa in 
Cardiganshire in a small basin mire on Banc Ty-llwyd (Fig. 8), and in quantity in the lagg swamp community at the west side of the Cors Caron raised mire complex. The galls are mostly oblong or slightly clavate, though some are subglobose (Fig. 7). The spores are mostly ellipsoid and smooth (Fig. 9), very unlike those of $E$. aschersoniana. Though previously unrecorded in Britain, it is likely to be found in many places where this host grows. It is the only species recorded on both families, as it occurs on Juncus filiformis in Europe (if indeed it is the same species - there are no sequences for it on either host in Genbank, accessed 3 Sep 2017), and it may well occur on this apparently increasing native species in Britain too.

In the twentieth century E. scirpicola was found in three sites in Scotland in 1979 and thereafter tracked down from one further site in Norfolk in 1915 on the basis of a herbarium specimen, parasitizing Eleocharis quinqueflora. Its occurrence in Britain was reviewed by Hooper \& Spooner (1981), who include a photograph of some impressive-looking galled roots. In spite of extensive searching by AOC, it has not been found in Wales, but PAS's searches in vc110 have turned up one specimen at Druim nan Carnan, Lewis in 2014. This was somewhat atypical, with a uniformly thickened root containing spores, rather than an obvious swelling, but clearly referable to $E$. scirpicola. The spores are obliquely striate (Fig. 10).

E. raunkiaeriana infects Eleogiton fluitans, and has hitherto been recorded only over a century ago from Denmark. It causes similar swellings on the roots (Fig. $13 \& 14$ ), and has been found on plants rooted in the substrate rather than free-floating. Its ellipsoid spores have 3-4 conspicuous, often oblique ridges in side view (Fig. 12). It has proved in 2017 to be widespread in mid Wales, AOC having found it in the swampy margins of three nineteenth century lead mine reservoirs (Fig. 11) and in swampy scrapes in the Aberleri Fields in Cardiganshire, in a moorland spring on Mynydd Llanybydder in Carmarthenshire, in Llyn Ebyr in Montgomeryshire, in Llynnau Cregennen in Merioneth, and Ray Woods has found it in swampy moorland pools in Radnorshire and Breconshire making a total of eleven tetrads in mid Wales.

Searching for material can be problematical. While Juncus bufonius is usually abundant where it occurs, and can easily, as an annual, be uprooted, other hosts are not so easily inspected or should not be damaged. J. articulatus and other perennial species of Juncus can require considerable effort to uproot and wash clean enough to see the galls. Carex limosa can, at many sites, be uncommon enough to make inspection of more than a few plants undesirable, although as it normally grows in waterlogged Sphagnum it can be put back in place with minimum disturbance.

Another species likely to occur in Britain is E. parvula on Eleocharis parvula, known only from the type collection from France, and the host is a Red Data Book Vulnerable species in Britain and should not be disturbed. Taxa on hosts that occur in Britain but that are not yet recorded even from Europe are E. casparyana var. tenuis on Juncus tenuis and E. fineraniae and E. globoidea on Isolepis cernua.

Cameron (1887), before the taxonomy of Entorrhiza was worked out, reported "E. cypericola" from Juncus squarrosus and J. bulbosus (as J. uliginosus). J. bulbosus is known as a host of $E$. aschersoniana (Vanky 2012), but there do not appear to be any other reports of a smut on the roots of $J$. squarrosus, so it may be worth looking out for it - though this is a particularly difficult species to uproot to search. In view of our recent findings, it seems likely that $E$. aschersoniana, E. casparyana and E. raunkiaeriana will all prove to be widespread and common in Britain, and E. caricicola probably somewhat less so. 


\section{References}

Bauer, R., Garnica, S., Oberwinkler, F., Riess, K., Weiss, M. and Begerow, D. (2015). Entorrhizomycota: a new fungal phylum reveals new perspectives on the evolution of fungi. PLoS One 10(7): e0128183. https://doi.org/10.1371/journal.pone.0128183.

Cameron, P. (1887) Biological Notes. IV Fungoid galls. Proceedings and Transactions of the Natural History Society of Glasgow 1: 298-300.

Fineran, J. M. (1978). A taxonomic revision of the genus Entorrhiza C. Weber (Ustilaginales). Nova Hedwigia 30: 1-68.

Hooper, S.S. \& Spooner, B.M. (1981). Occurrence of Entorrhiza scirpicola (Ustilaginales) on Eleocharis quinqueflora in Britain. Transactions of the British Mycological Society 76: 499-502.

Schwartz, E. J. (1910). Parasitic root diseases of the Juncaceae. Annals of Botany 24: 511-522 and Plate XL.

Trail, J.W.H. (1884). Two new British Ustilagineae. The Scottish Naturalist 7: 241-243.

Vánky, K. (2012). Smut fungi of the world. The American Phytopathological Society, St. Paul, Minnesota.

Zwetko, P. and Blanz, P. (2004). Die Brandpilze Österreichs. Österreichische Akademie der Wissenschaften, Wien.

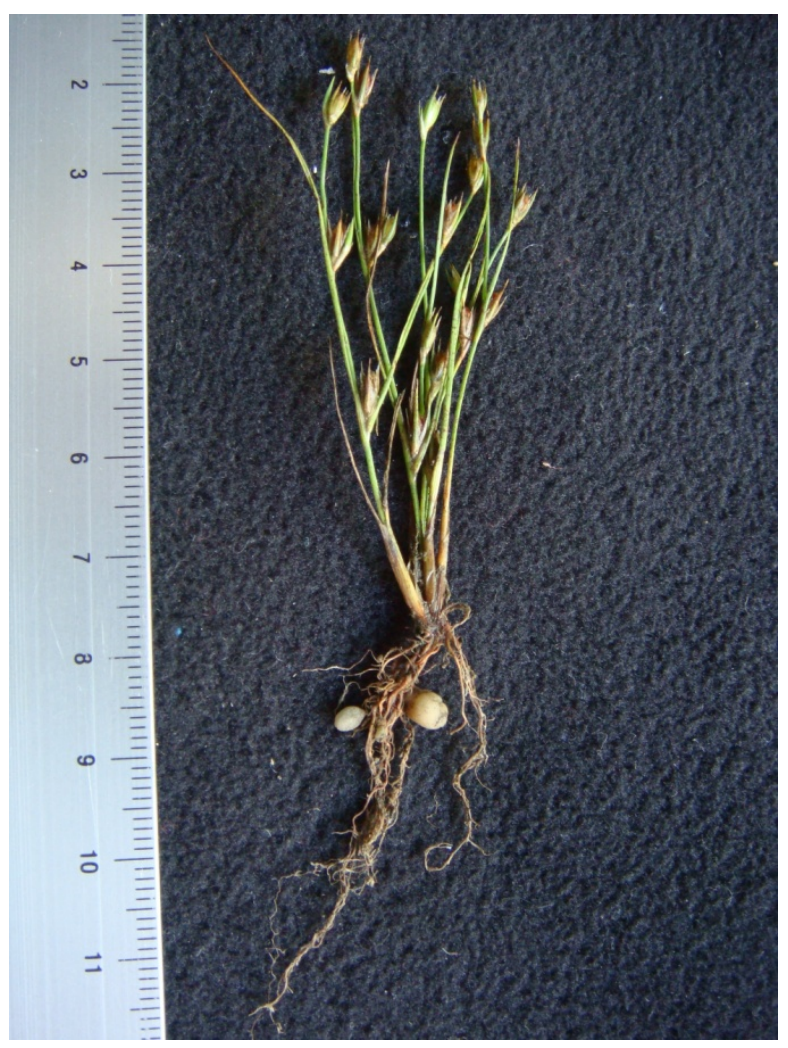

Fig. 1: Entorrhiza aschersoniana galls on Juncus bufonius, Ponterwyd, Cardiganshire, vc46. (C) A. O. Chater.

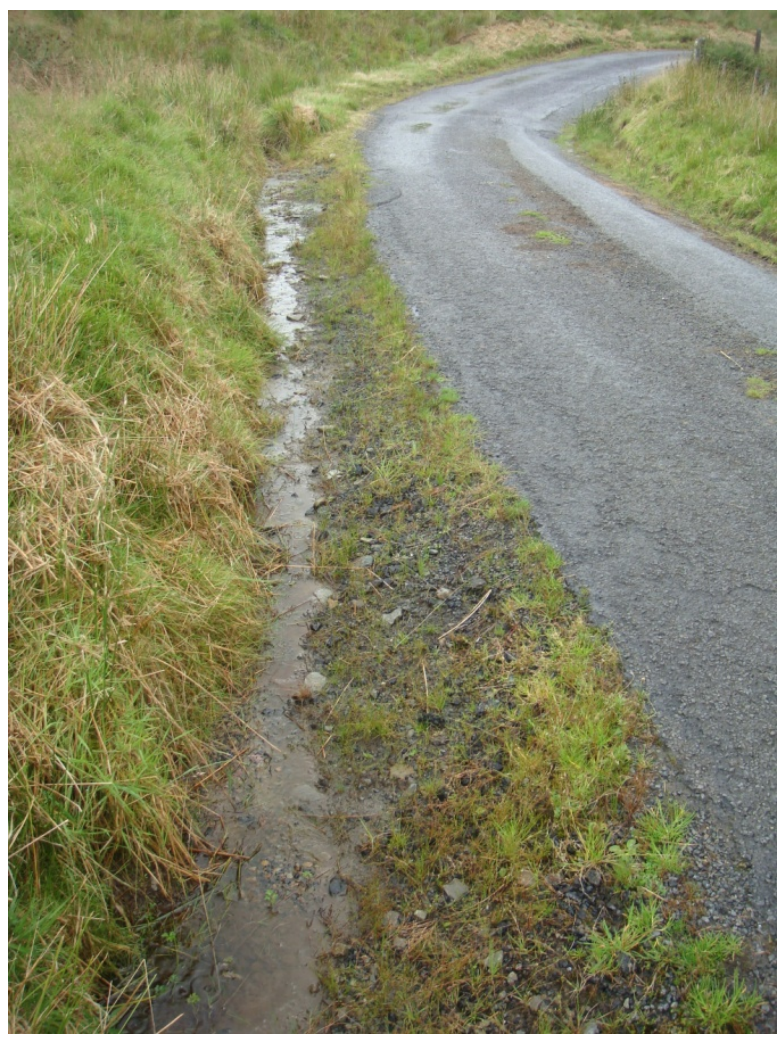

Fig. 2: Typical habitat of Juncus bufonius with Entorrhiza aschersoniana and J. articulatus with E. casparyana var. casparyana, Blaendoethie, Cardiganshire, vc46. ( A. O. Chater. 


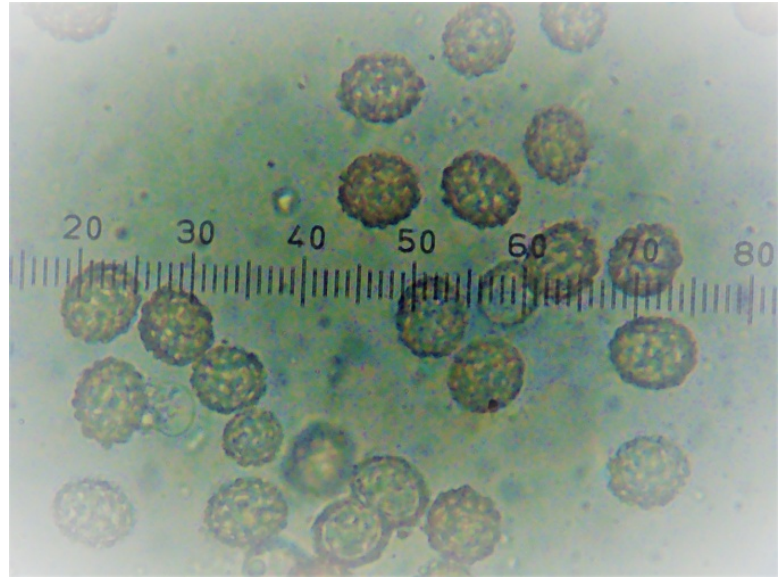

Fig. 3: Entorrhiza aschersoniana spores, Llanddewi-Brefi, vc46. (C) A. O. Chater.

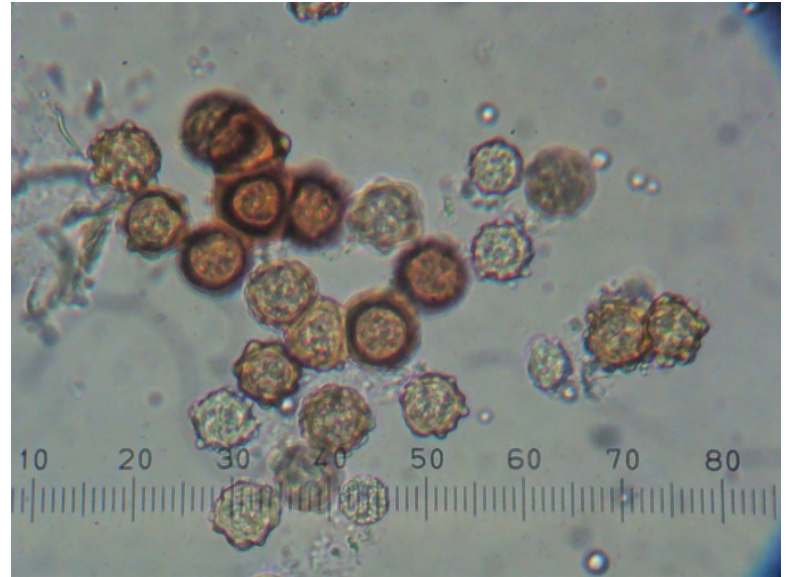

Fig. 4: Spores of Entorrhiza casparyana var. casparyana, Cyneiniog valley, Cardiganshire, vc46. (C) A. O. Chater

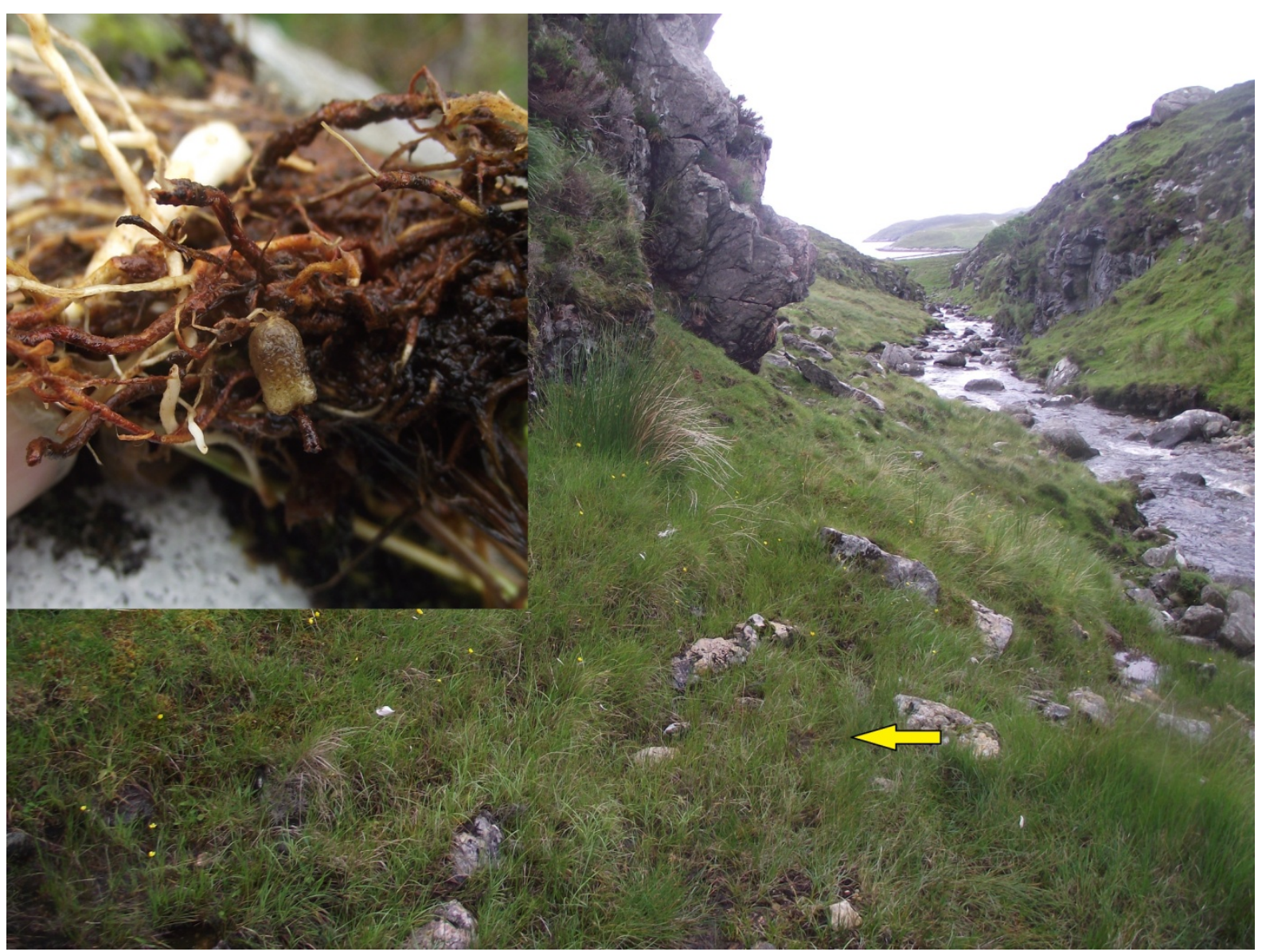

Fig. 5: Habitat of Juncus articulatus (arrowed) infected by Entorrhiza casparyana var. casparyana, Glen Skeaudale, North Harris, vc110, and (inset, centre) gall on infected root. (C) Paul A. Smith. 


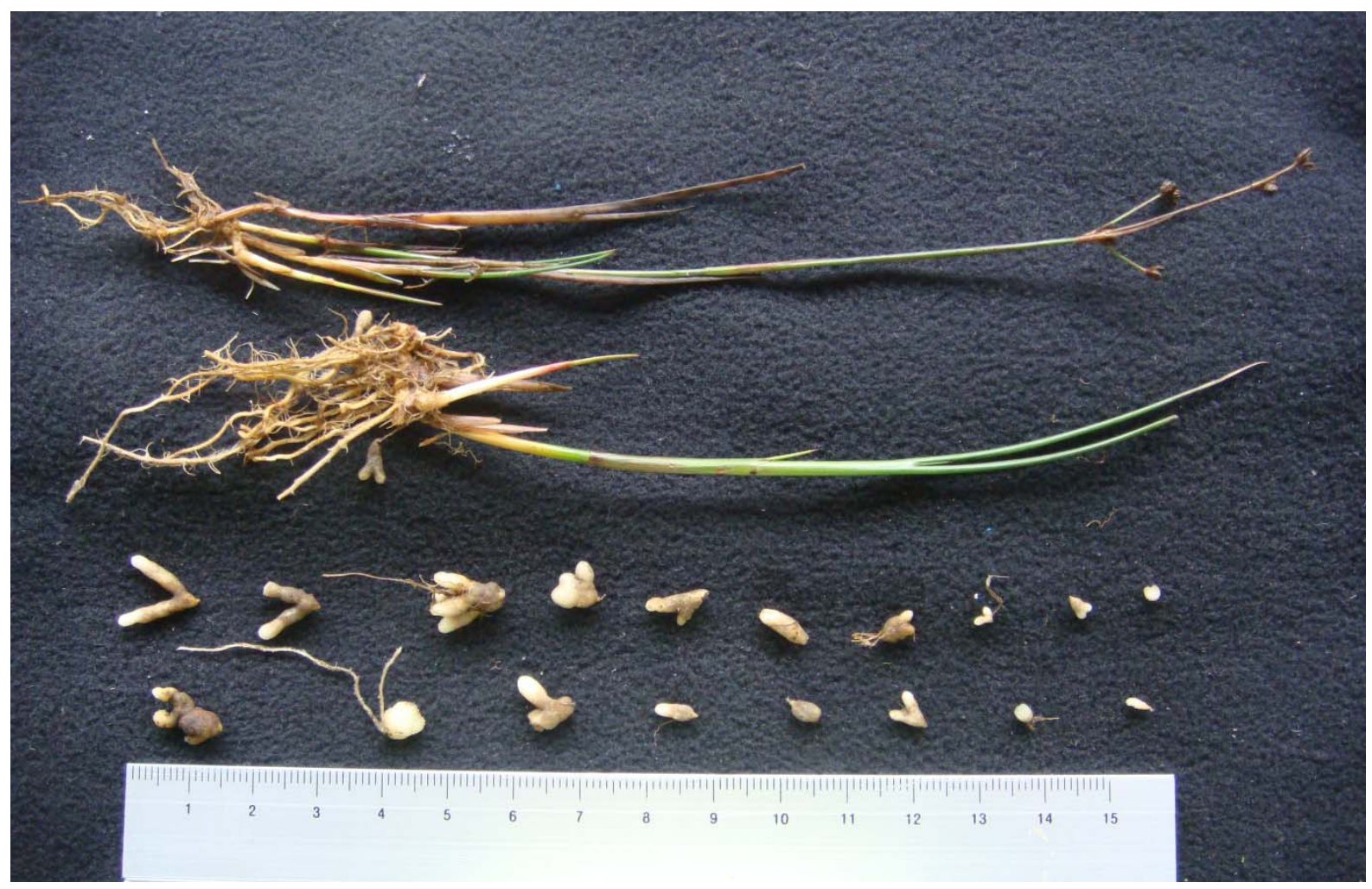

Fig. 6: Range of galls of E. casparyana var capasryana on Juncus articulatus from Ffair-rhos, Cardiganshire, vc46, showing the variation in size and digitation. (c) A. O. Chater.

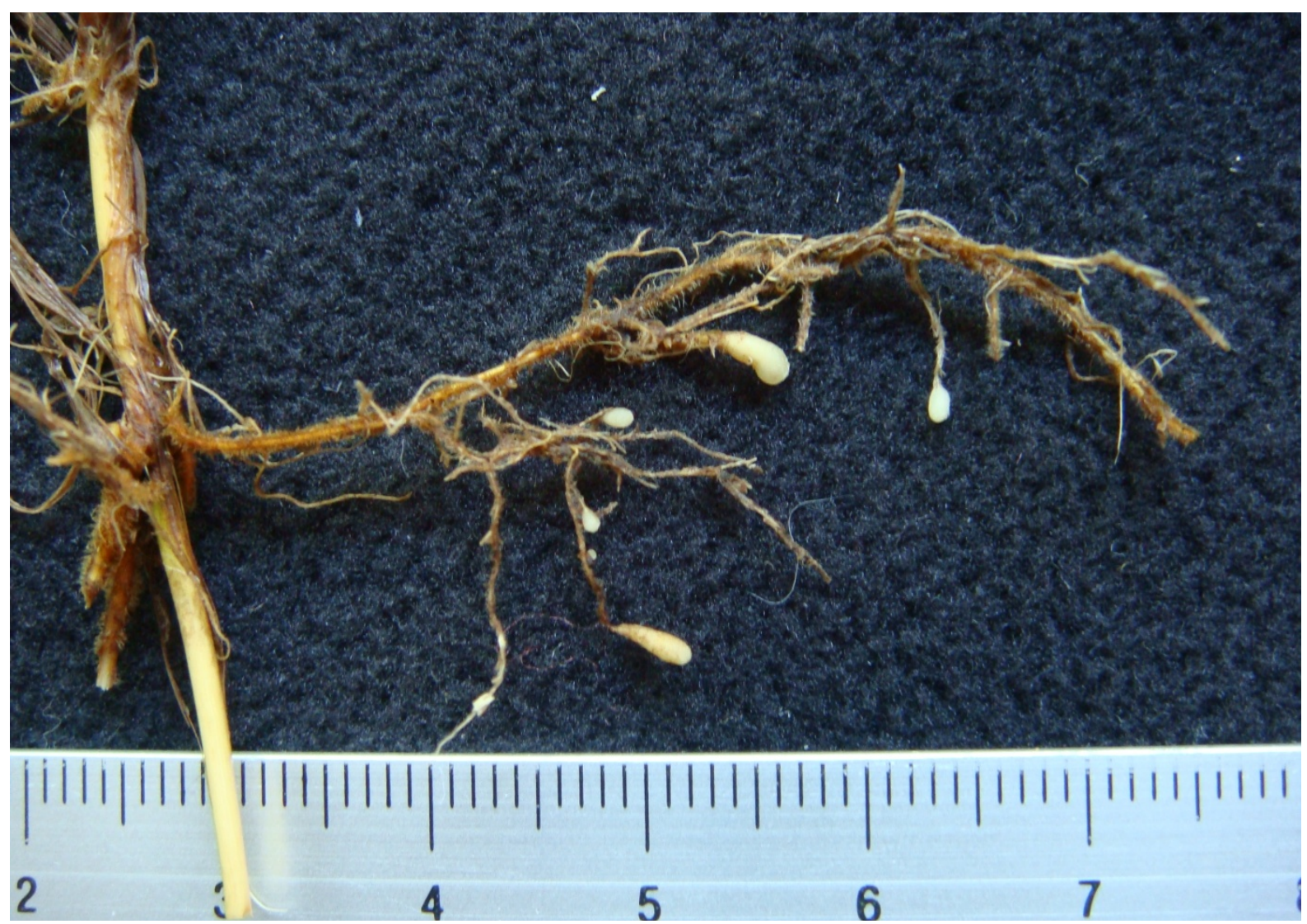

Fig. 7: Entorrhiza caricicola galls on Carex limosa, Cors Caron, Cardiganshire, vc46. (c) A. O. Chater. 

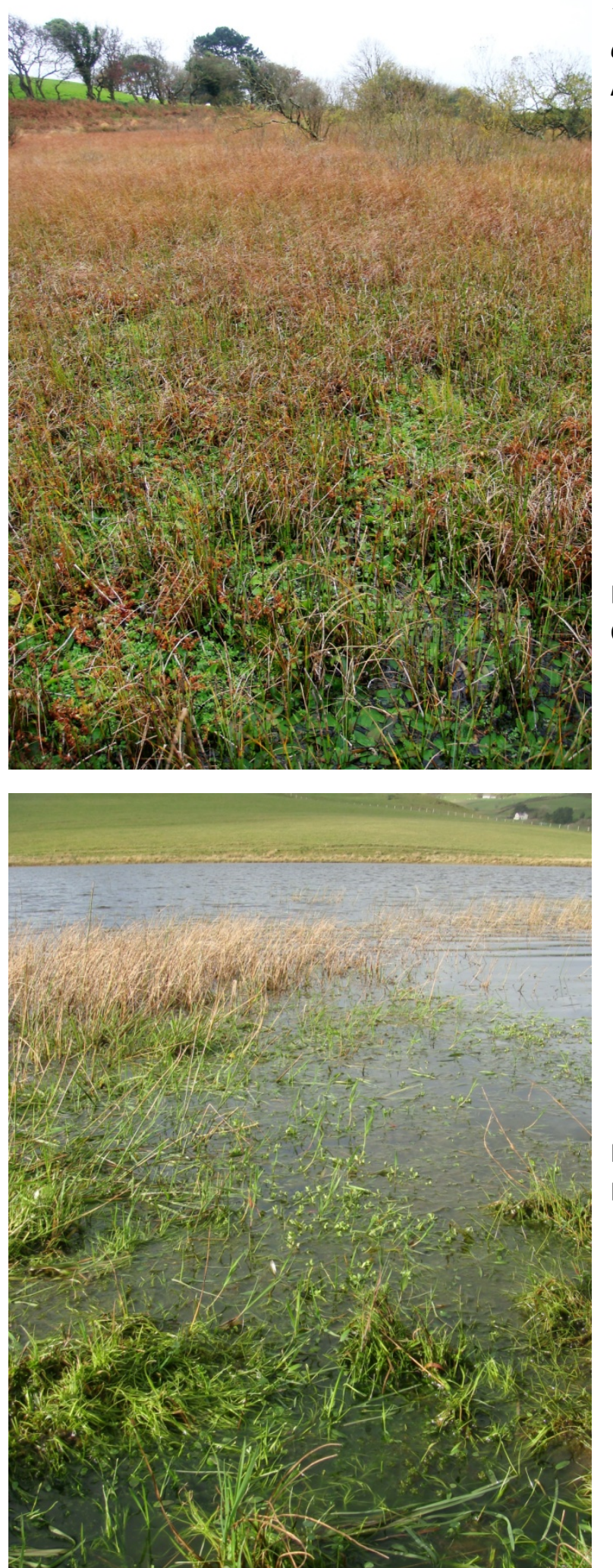

Fig. 11: Habitat of Eleogiton fluitans with Entorrhiza raunkiaeriana, Llantrisant Reservoir, Cardiganshire, vc46. (C) A. O. Chater.
4Fig. 8: Habitat of Carex limosa with Entorrhiza caricicola, Banc Ty-llwyd, Cardiganshire, vc46. (C) A. O. Chater

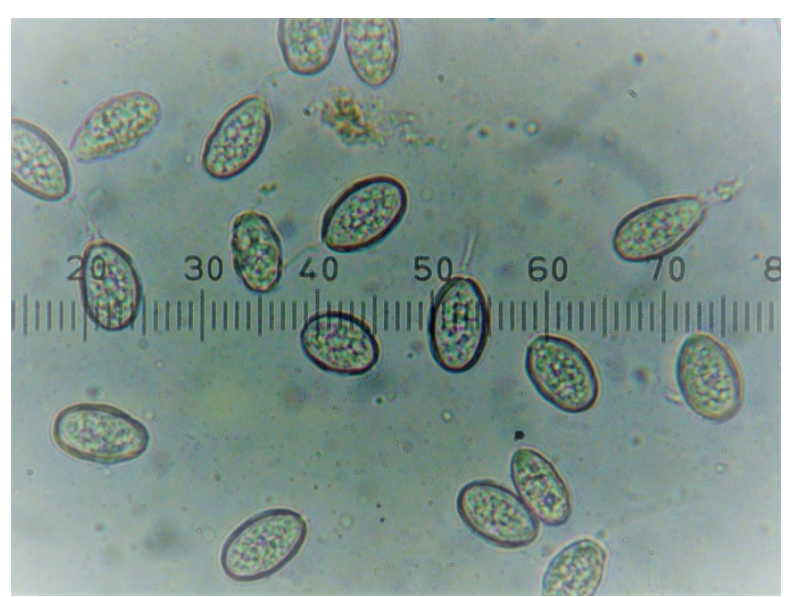

Fig. 9: Entorrhiza caricicola spores, Cors Caron, Cardiganshire, vc46. (C) A. O. Chater.

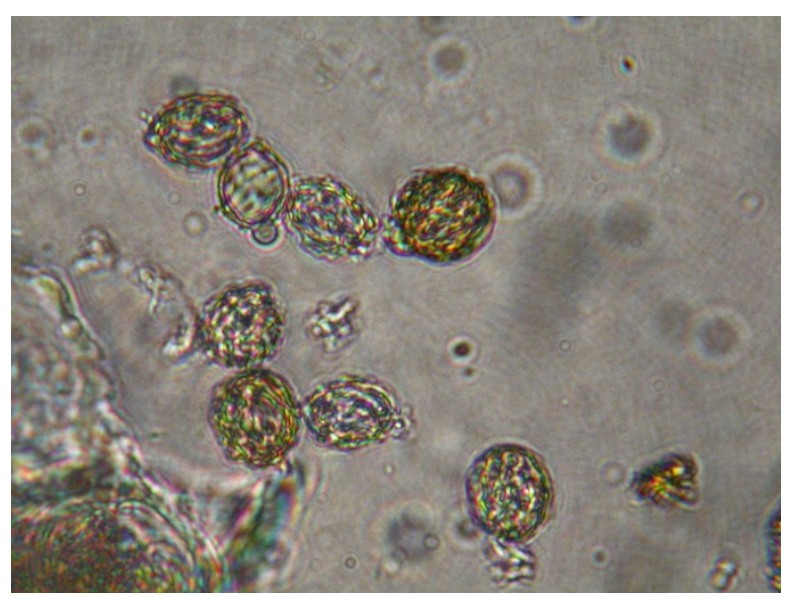

Fig. 10: Spores of E. scirpicola, Druim nan Carnan, Lewis, vc110. (C) P.A. Smith

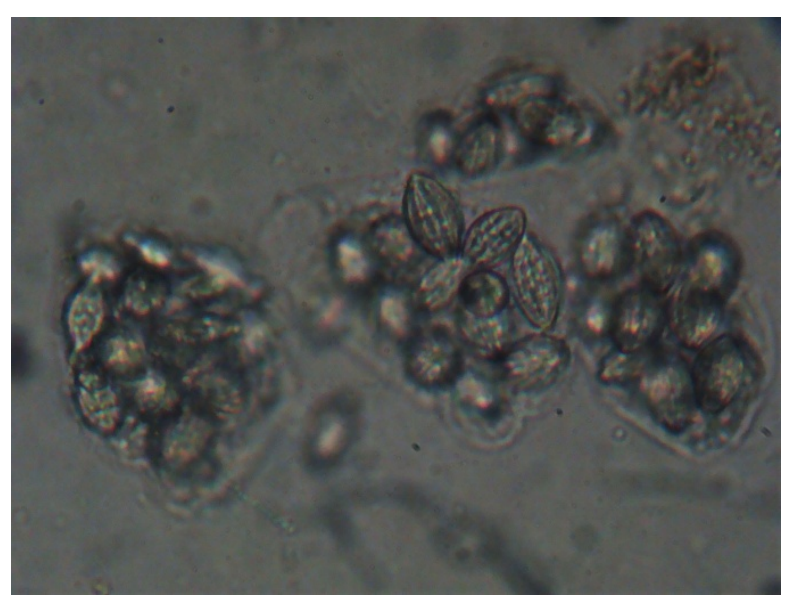

Fig. 12: Spores of Entorrhiza raunkiaeriana, Peny-cefn Reservoir, Cardiganshire, vc46. ( A. O. Chater. 


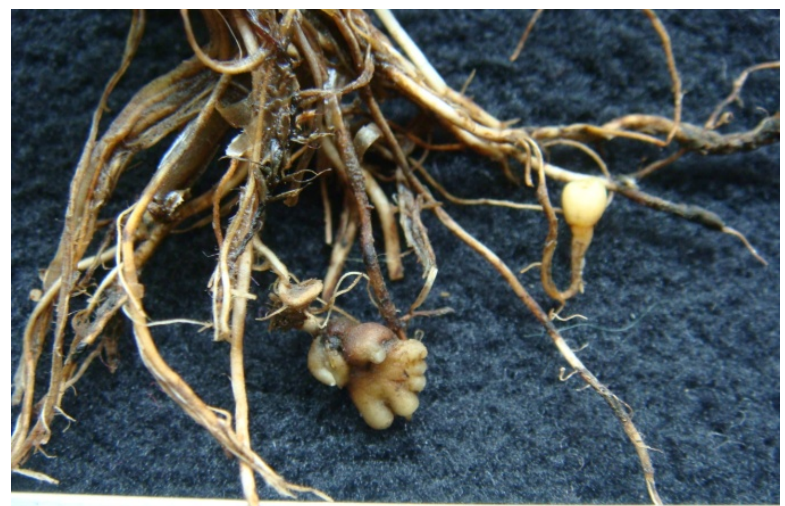

Fig. 13: An impressively lobed Entorrhiza raunkiaeriana gall on roots of Eleogiton fluitans from Pen-y-cefn Reservoir, Cardiganshire, vc46. (C) A. O. Chater
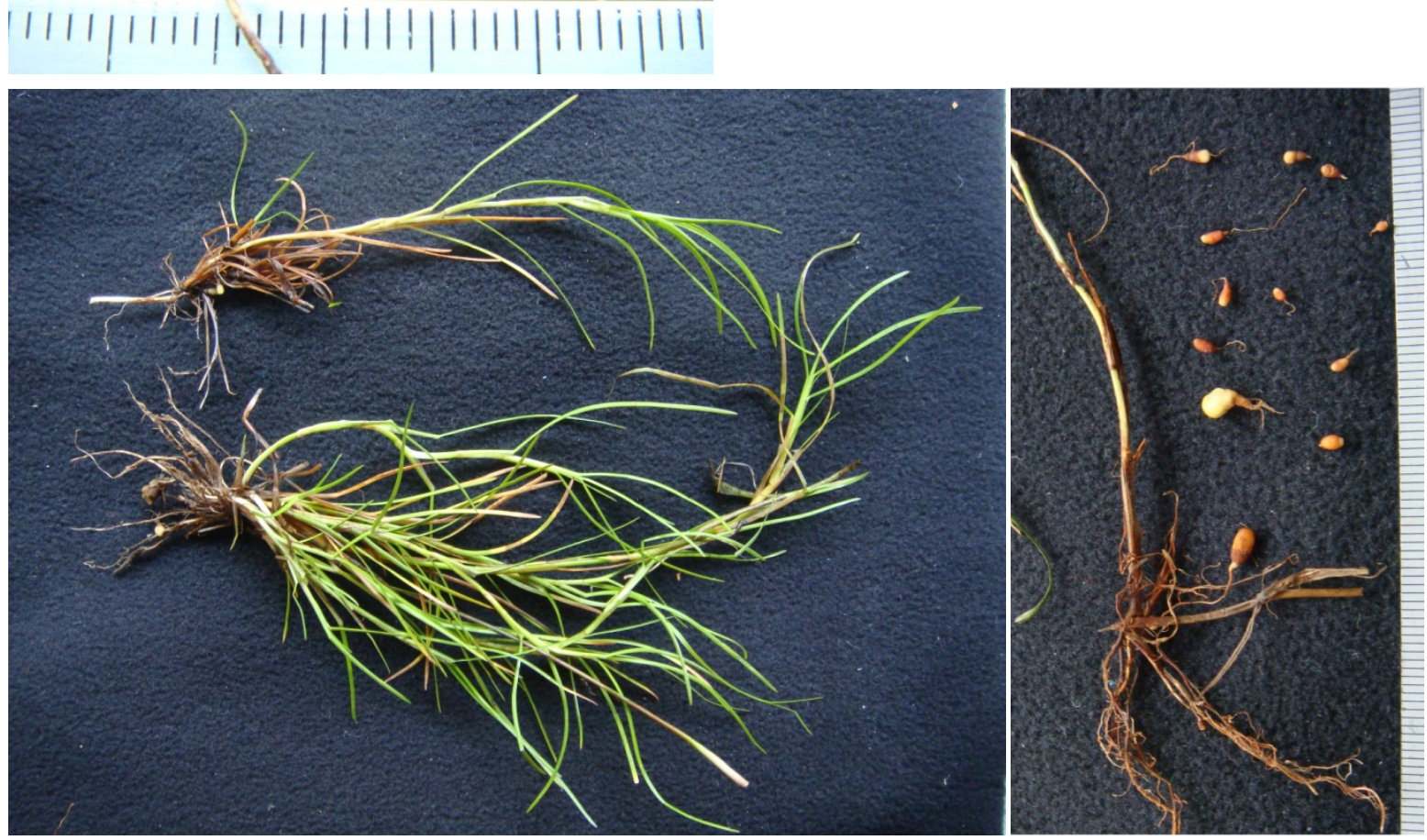

Fig. 14: Entorrhiza raunkiaeriana on Eleogiton fluitans, Pen-y-cefn Reservoir, Cardiganshire, vc46. (c) A. O. Chater. 